\title{
The objectness of everyday life: disburdenment or engagement?
}

\author{
Neil Maycroft \\ History of Art \& Material Culture \\ Lincoln School of Art \& Design \\ University of Lincoln \\ e-mail: nmaycroft@lincoln.ac.uk
}

This paper was originally published as 'The objectness of everyday life: disburdenment or engagement?', in Geoforum, Special Section on Material Geographies, 35 (2004) 713-725, (doi:10.1016/j.geoforum2004.03.013). 


\begin{abstract}
The increasing scale of designed objects forming our artifactual environment has been often noted. However, description, interpretation and analysis of this dense realm has generally proceeded through discussions of aesthetic attributes, semiotic significance and the meanings that such designed objects convey. This paper argues that this interpretative focus has occluded the extent to which the environment of consumer goods has been increasingly marked by the eclipse of the functional utility of such artifacts. Following the insights of Donald Norman, Albert Borgmann and Ivan Illich, three dimensions of usevalue, the cognitive, the experiential and the convivial respectively, are considered. The origins of a dynamic towards the eclipse of usevalue will be outlined and alternative approaches to understanding the practical significance of such designed objects will be advanced.
\end{abstract}

Keywords: use-value, design, cognition, engagement, conviviality

\title{
Introduction
}

Whilst it appears a straightforward proposition to equate everyday life with material objects it remains a relatively under theorised area in many commentaries. For example, it is ironic given the central role that Marxism assigns to the commodity form that it should actually profess little interest in the physical qualities of objects themselves beyond asserting the contradiction between their use and exchange values (though see Baudrillard, 1996). Rather, commodities are often represented as a simple means of linking the processes of production and consumption; they stand as ciphers. Yet the physical qualities of manufactured objects can reveal much. The focus developed here centres around the relationship between the physical nature of manufactured objects and the concept of use-value (Thrift 2003). As such, the following analysis does not focus on use as a social act of improvisation, neither does it concentrate upon the phenomena of either intended or unintended secondary, adapted use (Preston, 2000). The social relations of exchange are also largely left to one side (Gregson \& Crewe, 2003). Rather, the argument here contains two main emphases: Firstly, the extent to which usefulness is related to the object's intended and planned physical characteristics and, secondly, that a normative approach to use-value conceived in 
such terms is both insightful and warranted. The first theme rests on the idea that an object's purposefully designed material nature may suggest or allow a highly 'constrained' set of functional purposes (Latour, 2000) or invite a broad range of 'useful' possibilities. The second theme is supported by the belief that the objects of consumption are not neutral entities divorced from the normative concerns of a critical theory of society. Rather, the manner in which the physical characteristics of many objects mediate human action has substance for those wishing to advance such a perspective. Specifically, use-value here is explored through cognitive, experiential and convivial criteria

What of the geographical significance of such concerns? At this point they remain more latent than developed, mainly, perhaps, because I am not a geographer. Nonetheless, certain avenues of geographic exploration suggest themselves. For example, focusing on the cognitive attributes of manufactured products may lead into an appreciation of the 'micro'-geography of objects, to the geography of the object in use and so on. The resonance with time-geography particularly could be fruitfully pursued (see Jackson \& Thrift, 1995) as could the embodying of use-value through geographical object-relations approaches (Wood, 1998). The experiential dimension of use-value invokes the spatial relations of engagement with material culture, public-private, the spatial and temporal 'displacement' of engagement and so on (Willis, 1999), while a focus on conviviality draws attention to similar concerns (Schivelbusch, 1992). These will be foregrounded where possible.

\section{The 'objectness' of everyday life and rise of the sign}

Contemporary academic fascination with designed objects has tended to emphasise their semiotic and symbolic attributes. As this has coincided with an unprecedented differentiation and proliferation of available commodities some accounts have tended to see this as a primary point of demarcation between modern and post modern societies (see Featherstone, 1991). This emphasis on the cultural meanings attached to objects has drawn attention to their visual significance and the messages they are seen to carry in relation to memory, ritual, identity construction and so on (Shields, 1992). Everyday life, it is argued, is becoming increasingly 'aestheticised'; firstly, the 'design' component of commodities is seen to be increasingly important in assigning 
value and, secondly, the marked aestheticised and stylised look of the objects to be consumed is stressed (Featherstone, 1992). The 1980s, as both the decade of post modernism's ascendancy and as the 'Design Decade', captured this aspect well. It is argued that consumers encourage and demand such aestheticisation in that they treat the objects of consumption as primarily signs rather than as tangibly useful objects, eschewing the supposed 'functionalist logic of use-value' (Attfield, 2000: 85)

Despite the fact that historical comparison carries particular difficulties, current conditions can be regarded as an intensification of processes of aestheticisation that have a long history. For example, the ostentatious development of arcades, window displays, and department stores, at the end of the nineteenth century, mirrors the increased aestheticisation of the contemporary period. During the twentieth century manufacturers have often emphasised the aesthetic qualities of commodities through Worlds' Fair, Ideal Homes' Exhibitions, aggressive advertising and pronounced product styling. Whilst such techniques were used in the 19th century in connection with a growing provision of consumer goods which were aimed at affluent social groups, it is only since the latter 20th century that such techniques have been explosively elaborated.

The separation of the spheres of production and consumption results in a commodity form devoid of physical clues as to the social relations of its production and this vacuum of meaning is of immediate advantage to capital as the exploitative relations of its production are hidden from view (Lee, 1993). However, this lacuna also provides promotional industries with a ready made opportunity to produce a set of substitute meanings that may both further obscure the nature of productive relations and attach altogether different meanings to specific objects. The chief ways that this can be done are through advertising, packaging and commodity aesthetics and retail display. The promotional industries of capitalism have explosively developed such techniques in their attempt to naturalise the experience of proliferating consumption. For example, commodity aesthetics, or product styling, has developed many novel aesthetic and representational forms in order to fill the gulf of meaning that the commodity form displays (Haug, 1986). From the 1920s and 1930s onwards the proliferation of mass produced relatively affordable, standard goods was accompanied by a new commodity aesthetics -'form follows function'- an emblematic motif of modern design. Such functional design was itself the correlate of standardised, mass production based 
on long-run, interchangeable components and, later, planned obsolescence. A new form of aesthetics developed through which concepts such as speed, efficiency and progress could be represented. Such aesthetics were part of a mode of cultural regulation, according to Lee (1993), which aimed to ease the 'transition to modernity'. In contrast to Europe, in America this developing industrial aesthetic was quickly attached to consumer goods and their marketing. For example, streamlining had originally been developed in aviation technology to counteract wind resistance. However, from the 1930s onwards it could be found on myriad products both within the transport field and outside. All manner of commodities that never experienced drag were covered with symbolic aerodynamic pretensions,

... the relevance of the tear-drop look became completely unclear when applied to such things as refrigerators, stoves, meat-grinder handles, electric irons, orange juicers, and radios, Wind resistance seems a strange preoccupation for the designers of such products (Packard, 1960: 119)

What streamlining was able to do was to bring characteristics of the capitalist mode of production -speed, progress, efficiency-and attach them to the commodity form. According to Ewen (1976), streamlining provided a symbolic solution to the problem of how the ideals of capitalist modernity could cut through the traditional cultural values and insinuate themselves in everyday consciousness with the least popular resistance (see also Lichtenstein, n.d.).

The 'temporal aura' of such commodities was often purposefully forward looking. The use of materials, colour, and shape and the incorporation of sophisticated technological symbolism into everyday objects carried particularly optimistic meanings. For example, images of atomic structures, rockets, and molecular crystalline structures all proliferated in the 1950s and 1960s on fabrics, wallpapers, and the most mundane of consumer commodities. Such imagery reflected the faith placed in the advanced sciences of the day. The short term anticipation of new commodities and, the longer term expectation of a technologically driven superabundant future were both explicitly part of the material structure of many consumer objects.

In contradistinction, the post modern commodity often seems to look backwards. Form and function have been increasingly distanced so, for example, one can buy technically advanced goods that have been styled in 
forms from a different era. This should not be regarded as a wholly novel or post-modern development. The early twentieth century reaction of both Art and Crafts and pioneer modernist designers to Victorian ornamentation and stylistic recycling is notable. It is, rather, the intensification of such techniques that helps define the post modern articulation and, certainly, such techniques have flourished in the last fifteen years especially (Whiteley, 1994). Bricolage, eclecticism, montage and pastiche are all used, along with increasingly rapid turnovers in style, to emphasise an incongruence between function and presentation. Examples include vaguely familiar 'retro' designed goods such as radios which are composed of an ersatz Bakelite shell around up-to-date technological components or, explicitly technologically advanced goods which make allusions to the past through their styling. The first iMac computer with its 1950s' cartoon-like carcass or the Dyson vacuum cleaner with its entirely superfluous plastic and non-functioning heat dissipation fins are noteworthy here. Many multiple 'readings' of the meanings of such objects are seen to be possible in our almost pansemic material culture.

It has been argued, however, that the 'sensory overload', that results from the processes of rapid stylistic turnover and commodity differentiation, is a form of 'semiotic pollution' which makes it impossible to read any stable meanings into post modern commodities,

...the multiplication and continuous transformation of forms, colours, and textures of objects can lead to the impossibility of reading any real difference and real meaning in them. So it can follow that all these colourations and extravagances form a complex image that is confused, grey, and flat...The multiplication and change in products are going forward at such a rate that far exceeds the subjective capacity to develop codes that permit reading their possible significance (Manzini, 1995: 241).

This criticism captures the sometimes excessive contemporary enthusiasm for reading practically any narrative into any cultural product: if objects are semiological overloaded then, whilst their real meaning as commodities in the exploitative political economy of capitalism remains obscured, many possible interpretations and meanings can be generated from the wealth of semiotic material available (Gottdiener, 1995). 
However, the extent to which such commodity aesthetics, along with advertising, are successful in generating a will to consume has been a matter of debate. Many accounts of consumerism overstate the degree to which such strategies, especially advertising and its attempts to engineer false needs, have been successful (Packard, 1957). Some are altogether more cautious about the susceptibility of people to the ideological manipulation associated with advertising and other meaning generating techniques (Lodziak, 1995, 2002). Batchelor (1994) maintains that where mass production existed it was never as homogeneous as many accounts assume. Once product differentiation, seasonal and technical obsolescence, and niche production have been considered, the idea of uniform production of standardised commodities for a universal market becomes largely mythical and, hence, the promotional meaning making strategies that are seen to be derived from such techniques become questionable.

\section{The slow erosion of use-value?}

It can be argued that use-value used to matter more than it does now. Product design, especially, used to be more clearly about use-value, adding utility to goods to make them function in a safer, more predictable, more rational, and more efficient manner. Whilst adding economic value in order to increase profits, and adding sign-value in order to give meaning have always both been important to design in market economies, nevertheless the 'power' of design was publicly seen to be manifested in its ability to increase utility, adding use-value through improvements in function, in performance, in safety, in convenience and, in ease of use.

Of course, design does add intended use-value to products in many ways. The increased safety of many household objects has often come about from the efforts of designers to minimise the risk of injury and ill-health that could result from poor design. Treatments and fabrics that retard the spread of flames, devices that switch off electric equipment if left unattended, automobile air bags and so on. However, designers are often responding to legal safety requirements set from outside of the design professions and not coming from within. Consumer design also adds use-value in terms of convenience. A caveat is again in order though. Many labour-saving devices produce more labour, and many time-reducing technologies simply increase the work one has to do (Whiteley, 1994). The improved technical performance of consumer 
design goods also merits mention as an addition of use-value. Ever faster, more powerful electronic communications devices would be a prime example in this category. Yet, again we must acknowledge that many of the claims made for strict utility on this score are questionable. Is a computer that potentially may save you half a minute over the course of an hour's work but which demands increased time in order to learn its 'advanced' features really more useful (Eriksen, 2001)?

There are, however, factors that indicate a general decline in the level of use-value offered by much contemporary product design. Firstly, there is the common complaint of product obsolescence. Technical obsolescence commonly refers to the design of certain components such that their failure point can be calculated and predicted to occur prematurely in relation to the product as a whole. Stuff is designed to wear out sooner than it could or perhaps should. There is also stylistic obsolescence or fashion which by definition is the premature redundancy of myriad objects due solely to their semiotic attributes having been deemed 'out-of-date', usually by the industries which produce and promote those goods but also by consumers. The critique of all 'built-in' obsolescence in general finds its fullest expression in the work of Packard (1960) which, though dated, still generally pertains. Planned obsolescence is not necessarily the result of evil, profiteering designers secretively including crucial but fragile components. Indeed, social legislation has aided in protecting the consumer from such practices. Rather, obsolescence is an inevitable consequence of the development of consumer design products within the political economy of capitalism. Inter-firm competition, the need to maintain and increase one's market share and profits and the necessity to 'externalise' costs, generate this tendency towards built-in obsolescence ${ }^{1}$.

The increasing separation of engineering from surface design also works against many claims made in favour of utility. Designers of consumer goods themselves increasingly have less knowledge of the sophisticated components comprising many products, they often simply style the surface carcasses. Consumers may have even less knowledge of these mechanisms. This situation is worsened as many contemporary product carcasses physically do not allow access to internal mechanisms. Completely sealed units denying access or, with access made available only via specialised tools, is bolstered

\footnotetext{
${ }^{1}$ Such processes challenge claims concerning the environmental advantages of 'green' product strategies such as 'design for disassembly (DfD)', recycling, and 'product-service webs' (Maycroft, 2000).
} 
by warranty agreements that become void if attempts are made to dismantle the products. Safety and fragility may be reasons to deny access but are overplayed. It used to be a vital part of vernacular everyday culture that home repairs to many products could be affected with the acquisition of some know-how and patience. This autonomy, in relation to both repair and in relation to simply learning to understand the nature of the designed artifactual world, is diminishing in a world in which shoes cannot be resoled and radios cannot be opened. Technical and legal constraints help prevent its re-emergence in relation to new products.

If many contemporary accounts of material culture have emphasised appearance, they have, conversely, minimised the significance of use-value except where the symbolic use of objects has been interpreted as an aspect of use-value itself (Miller, 2001). Not only do people symbolically 'reuse' commodities once they pass into everyday life, they also invest then with new and varying use-values. A banal example would be the multiple use to which a daily newspaper may be put (cleaning, packaging, fuel, pet bedding, etc) none of which are explicitly intended by the producers of that commodity. It is the fluidity of use-value that challenges those accounts of consumption that locate the significance of commodities entirely in their symbolic dimensions. However, there is no widespread agreement on just what the concept of 'usevalue' means and the preceding discussion offers only generalities and vague intimations. Most of the objects which pass from saleable commodities into everyday objects are clearly useful in some way or other. The same is true of the raw materials, ingredients or partially assembled components which acquire their intended purpose after they have been productively worked on. What is offered here is a three-dimensional account of use-value derived from disparate yet overlapping analyses of material culture. It represents an attempt to develop a multiform consideration of use-value which can be used as a way of both judging the usefulness of objects as well as indicating the manner in which particular objects gain their peculiar significance as more or less useful in particular situations and in relation to particular modes of interaction with the people who use them. This approach considers the cognitive, experiential and social approaches to use-value. 


\section{The cognitive approach to use-value: 'constraints', 'af- fordances' and 'tacit' design}

Norman (1988) has both defended the power of design as a socially reforming activity whilst exposing its often poor cognitive character. Door handles that cognitively invite pulling but that need to be pushed, sign systems that do not tell you where you are, and arbitrary mapping between control features and the functions they initiate have all been detailed by Norman, as well as a series of alternative cognitive design criteria. On the one hand, we have increased the use-value or functional scope and efficiency of many objects and devices via technological means, whilst, on the other, use-value is undermined by the frustration caused by lack of cognitive comprehension. For Norman, this inability to successfully use objects is in very large part down to poor design of the goods in question. He notes that helplessness in relation to many domestic consumer products is commonplace; the familiar amusement expressed concerning the inability to programme video recorders for example. If an object requires labels, instruction manuals, expert operators, training sessions or warning stickers, it is, for Norman, indicative of poor cognitive design.

Norman groups his cognitive complaints into a series of categories which can both indicate the erosion of utility of a object and suggest 'cognitive' remedies through 'natural design': 'visibility', 'mappings', 'affordances' and 'constraints'. Good 'visibility' is that which enables us to immediately recognise the salt cellar from the pepper pot while too much visibility is the cognitive problem in relation to many electric devices and computer software: too many identical buttons having different functions or, too many menu and submenu commands to choose from. 'Mapping' refers to the relationship between the controls on an object and the functions they initiate. Many devices have far more operations than controls (the office telephone or digital watch), fail to indicate when an operation has been successfully, or unsuccessfully performed (lack of feedback from the video recorder that it has correctly been set) or fail to take advantage of 'natural' mapping (the way that the position of light switches in a room does not correspond with the position of lights). 'Affordance' refers to the 'perceived and actual properties' of the object or device in question and they 'provide strong clues to the operations of things' (Norman 1988: 9). For example, flat plates are for pushing, knobs for turning, slots for inserting things into. Many objects do not take advan- 
tage of such affordances such as when doors have flat plates which require pulling and are, hence, usually accompanied with a sign instructing one to do the opposite that cognitively the object's affordances suggest. Conversely, 'constraints' control or at least suggest what is not possible. They are used to prevent the wrong thing from happening. The unidirectional bezel on quality diving watches is an excellent example of a constraint. Constraints can be physical as in the above example, semantic such as knowing the one meaningful direction to face on a bicycle saddle, cultural, for example, the convention that red lights indicate moving vehicles should stop and green lights that it is safe to proceed or, logical such that when one is assembling an item of flat-pack furniture one logically assumes that all the sheets of 'MDF' are to be used as part of the final construction.

According to Norman, the cognitive usefulness of many objects has diminished over previous years for several reasons: the increasing functional complexity of devices which outstrips the user's ability to keep up, the pressures on all producers to maximise profits and thus externalise as many costs as possible including the research and development costs associated with the 'natural' design Norman advocates (though many of the same manufacturers willingly pay out great sums for the design of the complex information that goes into instruction manuals) and, the lack of 'tacit' knowledge of the designers themselves who are often not the end users of their own designs (Whiteley, 1994). It is Norman's belief that the incorporation of his design principles will lead to an environment of far more 'useful' and easily operated devices.

While Norman's approach lacks an insight into the political economy of consumer goods, as well as having been welcomed as part of an 'unexploited competitive edge' by business, it does at least suggest some interesting ideas about why some things may be functionally superior 'use-values'. For example, one object that has become very popular over recent years is the Roberts' or Bush post-war style radio. These are available as a 'retro' copy, rather than pastiche, using new materials and current technology. It is tempting to interpret the popularity of such an object in terms of semiotic explanations, that it appeals to a sense of nostalgia, either positively or negatively, that it revives memories of a different time and a different domestic and social culture. This may be so but, it may also be that such radios were in Norman's terms a very good piece of cognitive design. They had only three controls, an on-off switch, a volume knob and a tuning dial which featured 
the names of individual stations printed around it. Compared to the functional complexity and cognitive opacity of many contemporary radios, the attraction of such 'old' models from the functional point of view is easy to see. It may also be that with their 'engaging' under-geared tuning knobs and leather and wood components such radios 'disclosed' their properties much more than contemporary plastic or metal versions do.

However, Norman's approach rests on some questionable assumptions. Firstly, despite building his analysis on empirical observation, he tends to 'read-in' use-value in terms of cognitive deficiencies. There is neither an appreciation that the design fault may lay elsewhere or that cognitive behaviours are socially acquired and are highly changeable both within and across cultures. Our cognitive patterns may seem universal and 'natural' but they are not. The ethically and ecologically-minded designer Victor Papanek has shown how different cultures develop cognitive abilities which to us seem unlikely and incredible but which constitute part of the daily apparatus of the cultures involved. The Inuit ability to read text left-to-right, right-to left and upside-down is related by Papanek to the particularities of cognitively negotiating the environment they have traditionally inhabited (Papanek, 1995). Clearly, cognitive abilities and thus cognitive design criteria are to some extent culturally specific.

The second, and underlying, assumption of Norman's approach is that people are first and foremost information processors which again throws emphasis onto the cognitive attributes of the artifactual world. Offering alternative models of cognitive development does little to challenge this basic assumption and many would wish to offer other criteria for both their starting points in considering human behaviour, for example Actor Network Theory, and in terms of examining use-value (see Bingham, 1996, Miller, 1995a, 1995b). Indeed, Norman himself has recently emphasised the role that emotion plays in design and in the use to which people put products (Norman, 2004).

\section{The experiential dimension of use-value: 'engagement' and 'disburdenment'}

This aspect of use-value concerns the experiential 'qualities' of objects which are expressed in terms of the kind of 'engagement' that is offered. Borgmann 
(1995) gives the example of musical instruments as objects which deeply engage and television programmes as things that typically fail to engage. A user may turn to either to provide musical entertainment but where the musical instrument must be engaged with in order to make music, the television requires a simply push of a button on a remote control. Consider another example: one's need is for warmth and there are clearly a number of ways in which this heat could be generated. The most engaging would be the laying of a fire using materials that one had gathered. The least engaging or most disburdening would be switching on the central heating system. The history of capitalism has, according to Borgmann, been the history of growing disburdenment and of diminishing engagement as attention paid to the producing artifact has receded to be replaced by an immediate concern with the commodity produced, music or heat in the above two examples. Much of this has been technologically driven as improvements in the performance of materials and components has produced functionally more 'efficient' devices. In this, a certain amount of disburdenment has been welcome as it has freed people from many tiring and time consuming chores associated with the operation and maintenance of functionally simple devices. However, beyond a certain point, engagement is reduced to such a minimum that knowledge and understanding of the object itself becomes increasingly obscure. This produces further disburdenment, manifested, for example, in the inability to effect simple repairs. Increasing product elaboration and differentiation has seen the qualitative and quantitative exaggeration of this disburdenment as there is often little correspondence between the mechanical components and surface decoration of a given product. Disburdenment is then doubly reinforced as the complex mechanisms are increasingly hidden from view, and hence not open to engagement and, as the surface appearance of objects increasingly becomes disjoined from their functional capacities.

In calling for the rediscovery of engagement Borgmann highlights its spatial character asserting that, 'The world of engagement... has two principle settings, a large one in the city and a small one in the home; and both of these have a daily and a festive side' (1995: 17). Daily engagement in the city is manifested in everyday errands and spatial practices that appropriate public space including walking, sitting, reading, eating, and playing. Despite the increasing rationalisation of public space, such engagement is constantly recreated as new and old spaces are appropriated and reappropriated. There is also festive engagement in the city. Borgmann laments the destruction and 
neglect of communal festivity and urges its the return city life as a means of expressing and promoting such engagement (Borgmann, ibid).

Borgmann also seeks to distinguish between the everyday and festive modes of engagement in the home and daily engagement is manifested most obviously as housework. Whilst critical of both the highly gendered division of labour that characterises most housework and, the burdensome nature of many domestic tasks, Borgmann claims that it does at least represent the extension of people's selves into the texture of their own environment. He argues against the technological elimination of all housework, via the merging of automation with service industries and, also against its social elimination through the use of domestic servants. Technological elimination produces a sterile environment of highly disburdening devices while, social elimination is unjust and iniquitous (see Ehrenreich \& Hochschild, 2003).

Festive engagement in the home is best exemplified by activities including 'the culture of the table', conversing, story-telling and, the 'culture of musicianship' (Borgmann, ibid: 18-20). The culture of the table includes both activities of daily engagement such as the preparation, cooking, and cleaning up associated with eating but, these 'yield' to festive engagement through the 'celebration of a meal that engages and delights body and soul' (ibid: 18). In terms of the nature of the objects involved in such social practices, Borgmann draws a clear distinction. On the one hand, there are those "paradigmatic technological devices' such as microwave ovens, whose experiential qualities are primarily visual and which tend to reinforce disburdenment. In the case of microwave ovens focusing attention on the quick, clean and isolated production of a hot meal at the expense of engagement with the smell and taste of ingredients, the handling of utensils and the appreciation of the process of cooking. On the other hand, there are those objects that 'disclose' their properties including shape, weight, heat conductivity, surface texture, sound, and so on. Objects that invite engagement are distinguished by the multitude of their experiential qualities and by the disclosing power of those properties. For example, a weighty, sonorous frying pan which slowly accretes a patina from repeated use would be seen to be far more disclosing than a plastic microwave dish.

Borgmann's analysis perhaps licences a view which overplays the extent to which the recession of the artifact diminishes the significance of the commodity produced. For example, many may well take a complacent attitude to the production of home heating, seeing only the central heating thermostat and 
an on/off switch. But what if the heat produced is used to warm a room in which the production of thoroughly engaging activities takes place, learning a musical instrument for example? The temporal and spatial displacement of engagement is also significant in this regard. A pragmatic attachment to transport as a commodity does not preclude engagement at the end of the journey undertaken. Indeed, the search for engagement itself may become a laborious pusuit of an anticipated 'authenticity' of experience which constantly evades capture.

\section{The social context of use-value: 'convivial' tools and 'radical monopolies'}

Ivan Illich's notion of 'convivial tools' is a useful resource that can be adapted as part of a critical analysis of use-value. Illich uses the term 'disvalue' to describe how we, as a result of the increasingly commodified satisfaction of needs, become robbed of some quite narrowly defined abilities or skills (affecting simple repairs, basic cooking, knowledge of plants, flowers etc). According to Illich, though, this loss of skills is also the loss of the self-determined inter-connective 'moments' of people's everyday lives. This comes about as a result of us making fewer collective choices for needs satisfaction and increasing our dependence on private consumption. For example, mass personal ownership of garden equipment lessens the occasions when one may interact with one's neighbours through borrowing such items, devalues borrowing and sharing and undermines the exchange of vernacular, local or specific knowledge regarding gardening conditions. Such practices tend to be replaced by a narrower range of expert and commodified alternatives. Consequently, the production of nonmarketable use-values via convivial tools is placed at the centre of Illich's account. Tools is a broad term which signifies more than just the practical hardware of everyday life and Illich offers criteria for judging the conviviality of a particular tool: 'Biological Degradation', 'Radical Monopoly', 'Overprogramming', 'Polarization', 'Obsolescence' and 'Frustration'. 'Biological Degradation' refers to the ecological costs of current levels of production and consumption (Papanek, 1995). Much ecological destruction takes place either temporally or spatially displaced from the object either in production or after it has been discarded (though ecological destruction is also a result of use, e.g. the motor car) and, to various degrees, may be independent of the features of an object's immediate use 
being considered here. Energy usage and efficiency are aspects of 'biological degradation' that could be manifested in immediate use of an object; many functionally specific devices relying on batteries or fixed power supplies litter the domestic environment and Illich favourably compares hand tools to the mass of power tools and gadgetry which are routinely used to perform simple tasks.

'Radical monopoly',

By radical monopoly, I mean the dominance of one type of product rather than the dominance of one brand....Radical monopoly exists where a major tool rules out natural competence. Radical monopoly imposes compulsory consumption and thereby restricts personal autonomy. (Illich, 1973: 52-53).

Illich gives the example of how the undertaking industries have imposed a radical monopoly over burial and how building restrictions curtail one's autonomy to build one's own dwelling. The attempt of Microsoft to impose radical monopoly over computer hardware, software, file formats and operating systems is notable in this regard. Such radical monopolies tend to be implemented by and through structurally justifying organisations and institutions. Moreover, they tend to establish a coherent set of material objects. So, for example, with industrially produced food, the products are produced and grouped around variously functionally specific household appliances. The electric refrigerator, for example, exerts a radical monopoly over food cooling and storage as modern central heating produces over-warm domestic environments that require specialist food preservation technologies. Moreover, the pressure to reduce building costs provides a justification to build new properties without pantries for cool storage. Furthermore, many contemporary foodstuffs, using complex production techniques based on the use of high levels of artificial additives, actually require refrigeration in order to prevent premature spoiling. So, bread without preservatives, flour enhancers, and the like will gradually go stale (ie, still useable for breadcrumbs and certain recipes) in a pantry while bread containing 'preservatives' often quickly goes mouldy and unusable if not refrigerated.

'Overprogramming' occurs as people acquire ever more skills in relation to their tools at the expense of deeper understanding. As a consequence the sharing of knowledge tends to diminish as the dissemination of superficial 
information increases. There are a number of consequences; a reduction of general lay or vernacular knowledge and a rise of expert technicians, operators, repairers and servicers who defend their monopoly of expertise in relation to tools. For example, premium rate telephone lines often retain a monopoly of information and expertise in relation to domestic electronics as many such objects are 'overdetermined' often allowing little personal autonomy of use, repair or disposal.

'Polarisation' draws attention to the fact that the 'modernising' of poverty pivots around a dream of 'hyperconsumption' and abundance for all. The poor of industrialised societies are told that the solution to their poverty is represented by their potential to consume at the same levels as those of the rich. Although new commodities are continually presented as basic necessities high disparities of consumption obtain. This is true of the distribution of particular objects (for example, the exceedingly uneven distribution of personal computers and access to the world of 'on-line' information and services) and in terms of their cost of ownership. Leasing, for instances, is commonplace as a means of owning certain goods but, many on low incomes often have this as their only means of securing access to certain items. However, the costs incurred via this kind of ownership far exceed the average retail costs for such products. Moreover, the idea that leasing of this kind leads to manufacturers and retailers providing the most durable, well designed and environmentally benign commodities is contentious. It is often reconditioned, pre-owned and older, less energy and resource efficient models that are made available for leasing or renting.

'Obsolescence' has already been discussed above and Illich makes many similar points arguing that there is a constant lag between possession and what is available alongside a concerted attempt to convince us to replace what we have with what we could have. The attempts of the computer industry to get us to 'upgrade' both hardware and software at regular intervals is notable. Rapid technological development combined with technical incompatibility between systems, hardware and software all aid this dynamic towards obsolescence. The fact that many incompatible components are often manufactured by the same company through subsidiary divisions adds to the suspicion that obsolescence is indeed planned or 'in-built'. Illich also adds a critique of the unnecessary elaboration of products. The preponderance of the 'superfluous within the necessary' (Lodziak 2002), often unwanted features and unused functions, adds cost, ecological consequences and 'use- 
lessness'; that is, potential use which is never discovered or applied.

'Frustration' is the result of the 'negative returns' or 'marginal disutility' that occurs when 'ends become subservient to the tools chosen for their sake' (Illich, 1973: 79). Illich's well known example is the way in which a misapprehension that transport is concerned with increased speed of travel, rather than with saving time or energy, leads to the situation in which people drive fast cars two hours each way daily to work and back (time they would not spend walking or cycling). However, there are other common domestic devices, lauded for their use-value, which have similar effects: time saved mixing ingredients in a food processor can easily be offset by the increased amount of time required to assemble, prepare, dismantle and clean the object itself (Whiteley, 1994). The increased usage of scarce time is the most common disutility that accrues from the use of these non-convivial tools. The irony is that pressures on one's time often lead to the adoption of these 'tools' in the first place in a misconceived belief that they represent the solution to the scarcity of time experienced, just as the lure of the fast car lies in the mistaken belief that it will 'save' commuting time (Eriksen, 2001).

Convivial tools reduce 'overprogramming', 'polarization', 'frustration' and so on and allow for the autonomous production of use-values,

Tools foster conviviality to the extent to which they can be easily used, by anybody, as often or as seldom as desired, for the accomplishment of a purpose chosen by the user... They allow the user to express his meaning in action (Illich, 1973: 22).

Simple devices such as hand tools and services such as the public library system are convivial tools and, against those who regard conviviality as a return to pre-modern or craft based production, a common accusation, Illich argues that convivial tools are not synonymous with low technological content. As an example of a highly convivial tool Illich praises the public telephone system. Thirty years on we could cautiously include the mobile telephone, portable computers and other digital information storage and distribution technologies. Nevertheless, their remains an aura around Illich's ideas, and examples of concrete application, which suggests that the technology of industrial societies leads overwhelmingly to loss and impoverishment (Hoinacki \& Mitcham, 2002). In contrast, we may note that new skills and associated 
values come as readily into existence as they are lost. Digital communications technologies demand new skills as well as recasting the technologicalsocial-cultural matrix within which communication is perceived, defined and promoted. There is a notable spatial dimension to conviviality. Not only do established convivial spaces persist -libraries, allotments, pubs- but the constant re-making of conviviality produces new spaces, networks, activities and 'tools' such as Local Exchange Trading Schemes and the cultural ecologies of independent creative practitioners characteristic of many towns and cities (Shorthose, 2002) We can also note the spatial and temporal displacement of conviviality and the manner in which non-convivial tools can give rise to conviviality at different spatial scales; as one referee of an earlier draft pointed out, a non-engaging, paradigmatic and non-convivial tool such as an electric bread maker readily yields a product that may contribute to a both festive and convivial coming together at a different location.

\section{Relating the dimensions}

One is tempted to say that use-value is increased the more cognitive affordances an object has, the more engaging and disclosing it is and the more convivial its use potentially is. Indeed, one could build a kind of 'ethics' of use-value from this perspective. Such a perspective may be particularly attractive to ecologists or socialists in making normative prescriptions in relation to their respective critiques of overconsumption or reification. If, for example, particular products could be shown to be cognitively 'disarming', nondisclosing, non-engaging and anti-convivial then such considerations could be added to those of resource depletion, pollution, cost of ownership and so on. In a culture that promotes every invitation to consume as an opportunity to exercise choice rather than a cost, such analyses may provide additional critical ammunition. More romantically, just as Marcuse (1964) called for the 'aesthetic reduction' of technology to free objects from all oppressive and undesirable connotations while liberating their natural and life-enhancing potentialities, the call for a 'material reduction' of designed products could signal the desire to reject that which is cognitively opaque, non-engaging and anti-convivial. This, though, should not be made synonymous with Puritan calls for the rejection of all decoration or ornamentation.

More pragmatically, it is clear that certain objects may have a high degree of use-value in relation to one or more of the dimensions but not in 
another. The mobile telephone is an interesting example. Cognitively, mobile telephones tend not to be exemplars of good design; too many functions for the number of controls provided, a steep 'learning curve' in order to first use them, poor mapping etc (though the inclusion of displays and aural feedback increase their cognitive usefulness considerably). Experientially, mobile telephones are also lacking in 'usefulness'; engagement is confined to pushing buttons on the surface of the device and few properties are disclosed through the materials used in their construction. However, mobile telephones are a convivial technology. Once access to the network has been gained, they allow users to exchange all manner of information for an unlimited number of purposes and in different ways (voice, text, pictures, video, music). There is, of course, clearly a non-convivial dimension to the mobile telephone too. The aggressive marketing, promotion and upgrading of these objects would seem to confirm many of the dimensions of non-conviviality identified by Illich. There is certainly a strong flavour of radical monopoly in the manner in which they have come to represent communication itself. Text 'messaging' or 'texting', for example, has not only tended to conceptually diminish the value of other types of text messages (hand written notes, letters, postcards) with their differing spatial, temporal and cultural attributes but, has had real economic impact on the industries that produce writing paper, postcards and greetings cards. Increasingly fewer postcards are being sent and this draws attention to the fact that, although the scale and density of materiality in societies such as ours continues to increase, some aspects of our material culture may well be lost along with the associated skills and values which form the connective tissue of their use.

Other examples are equally as complex: the 3.5 inch computer floppy disc is cognitively excellent (it can only be inserted into the disc drive one way out of eight possible combinations), lacks engagement and disclosing properties but is extremely convivial (portable, shareable, ability to hold different kinds of information). We could counter pose Norman's approach to Borgmann's: certain musical instruments may be cognitively very poorly designed though engaging (bagpipes) while a microwave oven may be cognitively superb yet disburdening and so on. Of course, one may be thoroughly 'engaged' in the frustration and complexity of poor cognitive design in the same way that one would be in a puzzle. However, one chooses to engage with the complexities of a puzzle, one does not expect to be forced to negotiate such complexity when functional efficiency is called for. In fact, this kind of 'engagement' is 
really disburdenment and is largely independent of the disclosing properties of the object. Indeed, paying attention and engagement should not be made synonymous. One can be fully engaged but not paying conscious attention (playing an instrument) or paying full attention but not engaged (trying to programme a video recorder). This recalls Heidegger's distinction between an object being 'ready-to-hand' (engagement but not conscious attention) and 'present-to-hand' (attention with or without engagement, see Verbeek \& Kockelkoren, 1997).

The intention behind the acquisition of an object needs to be borne in mind $^{2}$. Potential users may be motivated by any combination of the dimensions of use-value discussed. One buys a video recorder primarily for its functional ability and not for its engaging or disclosing capacities. Conversely, one may acquire a musical instrument primarily precisely for the engaging qualities of both artifact and commodity. A second-hand item of clothing may appeal for little other reason that its disclosing power (Gregson \& Crewe, 2003). Conviviality of use may be the driving force behind the procurement of a personal computer for the family and so on. Any of these dimensions may overwhelm the others in determining the functional usefulness of an object in particular contexts.

\section{Useful and useless things?}

Which objects would satisfy the criteria that Norman, Borgmann and Illich propose, are there examples of outstanding use values? Consider the bicycle; cognitively, they are well designed displaying natural mapping, cognitive affordances, constraints of many kinds, visibility and feedback. The bicycle is also a highly engaging device requiring absorption in it as an artifact in order to produce its 'commodity' - movement. The bicycle is also convivial allowing many different kinds of user to use it for many different purposes and without impinging on the actions of others. Yet there is more to be said about such a commonplace object. Consider the role of technology; the ongoing development of bicycle technology at the 'high' end and its gradual transfer across the range of available bicycles can alter the relationship and balance between

\footnotetext{
${ }^{2}$ I use different verbs to denote acquisition deliberately as many accounts of consumption see little beyond the buying of commodities as though no one ever comes by anything via state provision, finding, stealing, sharing, borrowing, swopping, libraries, leasing or hiring (Gregson \& Crewe, 2003).
} 
the cognitive, experiential and convivial dimensions of use-value. For example, it could be argued that the cognitive opacity of bicycles is increasing. Consider integrated gear and brake levers; not only is it not obvious which levers are associated with which wheel (a bicycle design convention which is reversed on American cycles) but it is also not always clear which lever operates the brake and which the gearshift. The direction of lever movement is often also not cognitively mapped to the direction the chain shifts on the chainrings. More gears and integration may give more options and better performance but there is also more to learn and remember. The same point applies when one considers bicycle maintenance. Increasingly complex parts including suspension forks and seat posts require cognitive attention. However, this also increases the opportunities for engagement with the bicycle which for some enthusiasts may be welcome but for others may be seen as a burden. Conversely, it could be argued that engagement is decreasing; the replacement of friction gears which had to be 'felt' for with indexed gears which move the chain across the rings by a fixed amount, for example. Or, take the widespread use of cleated pedals; many cyclists initially complain that they are too 'engaging' connecting the rider to the bike to an uncomfortable degree. After, regular use however, this discomfort lessens as one becomes less aware of the cleat and the pedal becomes increasingly 'readyto-hand'. Convivial complexity can also be uncovered and Borgmann makes this very point in relation to Illich's championing of the bicycle as a convivial tool,
Illich,... would restore a more human scale to our dwelling and travelling by restricting all speeds to that of a bicycle, $15 \mathrm{mph}$... But what if technology gives us human-powered vehicles that allow us to move at $50 \mathrm{mph}$ ? Would not conviviality have to accept the present patterns of commuting and population distribution (Borgmann, 1984: 168)?

In the thirty years since Illich fixed the figure of convivial speed at 13$15 \mathrm{mph}$, technology transfer has, indeed, resulted in a situation where travelling at $17-19 \mathrm{mph}$ by bicycle is as easy as $13-15 \mathrm{mph}$ used to be. Geographers would be well placed to make telling interventions concerning the spatial dimension of conviviality; identifying the spaces, scales and technologies that would enable conviviality in action. 
Perhaps a negative approach would bear more fruit; what is the acme of non-usefulness in relation to the cognitive, experiential and convivial dimensions identified here? A quick trawl through two recent product catalogues, an 'Innovations' type consumer gadgetry booklet and the latest 'Bettaware' catalogue, reveals some interesting objects which, while they have a clear 'function', are not very useful from the perspective developed here. For example, we may argue that one does not need a 'battery powered spider vacuum' because not only does it represent a waste of scarce resources but also because it is based on a highly reified view of non-human nature as well as not being readily adaptable for any other purpose. Similarly, the 'Lean, mean, fat-reducing grilling machine' is highly functionally specific (draining fat from high fat foods) which obscures less technologically sophisticated means of achieving the same end using a simple frying pan, distances the user from the engaging activities associated with food preparation and invites incompetence in relation to alternative values and means such as thinking about the nature of the meat industry or buying low fat food.

Commentators who praise the choice, pleasure, meaning and even 'freedom' of consumption will take an antagonistic view of such an approach (Mackay, 1997). Apart from questioning consumer sovereignty and choice, the argument may be advanced that such prescriptions are an attack on the meaning that people derive from consumption. However, as many accounts overload acts of consumption with meaning and significance this must be expected (Fiske, 1989). For example, one product catalogue currently offers 'multi-use handy clips' and suggests that they may be used to re-seal open bags, clip together bills and so on. Basically, these clips are spring-loaded clothes pegs with two significant differences; firstly, they are many times more expensive than an equivalent number of pegs, and, secondly, they have been restyled into a variety of shapes and 'kitchen' colours such that they are argued to be more attractive and distinctive than ordinary pegs. An emphasis on the symbolic aspects of consumption may stress the meaning, pleasure and fun that the purchase and use of such objects may inspire; they may be a talking point for the family, they may be prominently displayed in order to attract the admiration of neighbours or friends, and so on. A focus on use-value would stress their conviviality but would ask what is their use-value advantage over ordinary pegs with their capacity for adapted and improvised functionality? The answer is that they have no functional advantage. The point is not particularly to denigrate their use as markers of 
meaning but, rather, to argue that accounts of their use may be tempted to overload them with such significance. They are pegs masquerading as 'handy' clips; useful, adaptable but prosaic. They may convey all manner of meanings to different people in particular situations but, they are not themselves meaningful in the sense of being significant. Overloading the most mundane of objects with significance helps to obscure other aspects of the political economy of consumption that may be more revealing (Lodziak, 2002). For example, would anyone's life be seriously diminished if one could not purchase 'Neuticles', prosthetic testicles for neutered dogs, which claim to restore lost 'self-esteem' to both the animals and their owners? Only the manufacturers and those who cynically construct and promote the idea that there is a need for them, that is, those who seek to attach significant meaning to their consumption.

In a more positive vein, some activities may illustrate the benefits of artifacts that manifest the functional, experiential and social dimensions of use-value. One reason why gardening, cooking and home improvement may be so popular could be to do with the use-value they encompass as well as the often commented on meaning they involve. All may feature the use of well designed implements that are cognitively 'transparent' as well as engaging through their operation. They require raw materials, tools and utensils that are replete with disclosing properties. The processes of production involved are also engaging and rewarding in terms of the experiential properties involved through the extension of one's self into one's environment though often they are practised alongside more routine technological provision using disburdening devices (Rybczynski, 1989). Additionally, such activities can be convivial in different ways; they represent the satisfaction of needs through the autonomous production of further use-values, they can be practised easily and by many different people, they may have a strong social dimension involving the sharing of equipment, know-how, end produce, etc., and be practised collectively. Despite the reliance on the commodified provision of raw materials and tools, and the relentless injunctions of media 'experts', such activities remain of interest here.

Commercially there has recently been a recognition that both cognitive usefulness and engaging capacity can be used as a competitive edge in product development and promotion (Press \& Cooper, 2003). Whilst some relatively small and high-end companies have long promoted themselves by making a virtue of clear cognitive design, it has, of late, found a much more 
receptive and widespread audience throughout industry. Similarly, providing engagement and disclosing power are increasingly becoming part of the brief of designers across many product domains. Recent examples include 'organic' product styling and its accompanying rhetoric (designing kitchen utensils such that they are regarded as a 'garden of objects' which invite attention, care and preservation, see Manzini, 1995), the move towards wood in much contemporary architecture, and the reappearance of materials such as leather and wood on electric equipment from cameras to radios. Manufacturers also engineer 'bogus' cognitive affordances and disclosing properties; car producers have been known to use heavy sounding door clicks in light bodied models, fabricated wood on plastic dashboards and leather aromas on vinyl seats. What is found much less often in contemporary consumer deign is a concern with the criteria of conviviality advocated by Illich. Of course, there is much rhetoric concerning sustainability and 'green' product development but, most professional product designers are tightly locked into political economic structures which demand the constant expansion of consumption and not the self-limitation that Illich calls for. As Billet observes '...it is rare to find designers who believe in less design, in terms of less products, less variety, less novelty and a life style of "conspicuous thrift" -rather than the norm of "conspicuous consumption"' (Billet et al, 1996: 3).

\section{Conclusion}

When the objects of material culture are viewed in the ways discussed above, it becomes increasingly challenging to define what use-value actually encompasses. Most of the commodities that become the objects of everyday life are obviously useful in some sense. However, to return to a point made earlier, the analysis provided here risks being accused that it is overloading something interesting with unwarranted significance. After all, what is being discussed is simply the shape, materials and components that comprise 'mundane' products. To an extent, this is true, such concerns are not central to a critical theory of society, rather, they are interesting but marginal. An egalitarian, democratic and open society characterised by 'poor' use-values is preferable to an unequal, undemocratic and closed society replete with 'excellent' use-values. However, the dimensions of use-value discussed above cannot be simply lifted out of broader concerns, arising as they do out of a political economy that promotes waste, obsolescence, functional specialisa- 
tion and commodification as the primary means of needs' satisfaction. The analyses offered by Norman, Borgmann and Illich do suggests ways in which to discriminate between objects that further de-skilling and disburdenment and those which help to restore conviviality, vernacular subsistence, and engagement. Geographers accepting such a challenge would have much to offer in this regard and, for all of those interested in the restoration of such values, this kind of analysis may be of some 'use'.

\section{Acknowledgments}

I would like to thank Ben Anderson for his support and encouragement of a non-geographer, probably a trying experience. In addition, I would like to thank the referees of an earlier draft, especially the fellow cyclist who made numerous perceptive and supportive comments.

\section{References}

Attfield, J., 2000. Wild Things: the Material Culture of Everyday Life. Oxford, Berg.

Batchelor, R., 1994. Mass Production, Modernism and Design.Manchester University Press.

Baudrillard, J., 1996. The System of Objects. London, Verso.

Billet, E., et al 1996. 'Editorial notes'. Co-Design 5/6, 1-4.

Bingham, N., 1996. 'Object-ions: from technological determinism towards geographies of relations'. Environment and Planning D: Society and Space $14,635-657$.

Borgmann, A., 1984. Technology and the Character of Contemporary Life. The University of Chicago Press.

Borgmann, A., 1995. 'The depth of design'. Margolin, V., Buchanan, R., (Eds) Discovering Design. University of Chicago Press.

Campbell, C., 1995. 'The sociology of consumption'. Miller, D., (Ed) Acknowledging Consumption. London, Routledge.

Ehrenreich, B., Hochschild, A. R., 2003. (Eds) Global Women: Nannies, Maids and Sex Workers in the New Economy. London, Granta Books. 
Eriksen, T. H., 2001. Tyranny of the Moment. London, Pluto.

Ewen, S., 1976. Captains of Consciousness. New York, McGraw Hill.

Featherstone, M., 1991. Consumer Culture and Postmodernism. London, Sage.

Featherstone, M., 1992. 'Post modernism and the aestheticization of everyday life'. Lash, S., Friedman, J., (Eds) Modernity and Identity. London, Routledge.

Fiske, J., 1989. Reading the Popular. London, Unwin Hyman

Gottdiener, M., 1995. Postmodern Semiotics: Material Culture and the Forms of Postmodern Life. Oxford, Blackwell.

Gregson, N. Crewe, L., 2003. Second-Hand Cultures. Oxford, Berg.

Haug, W., 1986 Critique of Commodity Aesthetics. Cambridge, Polity Press.

Hoinacki, L., Mitcham, C., 2002. The Challenges of Ivan Illich. State University of New York Press.

Illich, I., 1973. Tools for Conviviality. London, Marion Boyars.

Jackson, P., Thrift, N., 1995. 'Geographies of consumption'. Miller, D., (Ed) Acknowledging Consumption. London, Routledge.

Latour, B., 2000. 'The Berlin key or how to do words with things'.

Graves-Brown, P. M., (Ed) Matter, Materiality and Modern Culture.

London, Routledge.

Lee, M. J., 1993. Consumer Culture Reborn. London, Routledge.

Lichtenstein, C., \& Engler, F., no date. Streamlined: a Metaphor for Progress. Zurich, Lars Muller Publishers.

Lodziak, C., 1995. Manipulating Needs: Capitalism and Culture. London, Pluto Press.

Lodziak, C., 2002. The Myth of Consumerism. London, Pluto.

Mackay, H., 1997. (Ed) Consumption and Everyday Life. London, Sage.

Manzini, E., 1995. 'Prometheus and the everyday'. Margolin, V.,

Buchahan, R., (Eds) Discovering Design. University of Chicago Press.

Marcuse, H., 1964. One-Dimensional Man. Boston, Beacon Press. 
Maycroft, N., 2000. 'Re-valorising rubbish: some critical reflections on 'green' product strategies'. Capital \& Class Special Issue; Environmental Politics: Analyses and Alternatives 72, 135-161.

Miller, H., 1995a. 'The Social Psychology of Objects'. http://ess.ntu.ac.uk/miller/objects.htm. 27/6/2003.

Miller, H., 1995b. 'PC is to Mac as Mountain Bike is to Road Bike: towards a personality of objects'. http://ess.ntu.ac.uk/miller/pcmac.htm. 27/6/2003.

Norman, D., 1988. The Design of Everyday Things. London,Doubleday.

Norman, D., 2004. Emotional Design. London, Basic Books.

Packard, V., 1957. The Hidden Persuaders. Harmondsworth,

Penguin. Packard, V., 1960., The Waste Makers. Harmondsworth, Penguin.

Papanek, V., 1995. The Green Imperative: Ecology and Ethics in Design and Architecture. London, Thames \& Hudson.

Press, M., Cooper, R., 2003. The Design Experience: the Role ofDesign and Designers in the 21st Century. London, Ashgate.

Preston, B., 2000. 'The functions of things'. Graves-Brown, P.M., (Ed) Matter, Materiality and Modern Culture. London, Routledge.

Rybczynski, W., 1989 The Most Beautiful House in the World. Penguin, USA.

Schivelbusch, W., 1992. Tastes of Paradise: A Social History of Spices, Stimulants, and Intoxicants. New York, Vintage Books. Shields, R., 1992. (Ed) Lifestyle Shopping. London, Routledge.

Shorthose, J., 2002. 'Conviviality in global cultural development: diversity, freedom and agency'. Development:International Journal of Development Studies 45 (3).

Thrift, N., 2003. 'Closer to the machine? intelligent environments, new forms of possession and the rise of the supertoy'. http://www.ggy.bris.ac.uk/staff/information/thrift.htm. $27 / 1 / 2003$.

Verbeek, P. P., Kockelkoren, P., 1997. 'Matter matters'. Van Hinte, E., (ed) Eternally Yours: Visions on Product Endurance. Rotterdam, 01 Publishers. 
Whiteley, N., 1994. Design for Society. London, Reaktion Books.

Willis, D., 1999. The Emerald City: And Other Essays on the Architectural Imagination. Princeton Architectural Press.

Wood, J., (Ed) 1998, The Virtual Embodied. London, Routledge. 